\title{
LAMANYA KLIEN MENGALAMI GANGGUAN JIWA DENGAN STRES KELUARGA DALAM MERAWAT KLIEN DI RUMAH
}

\author{
Dyah Widodo 1 \\ ${ }^{1}$ Poltekkes Kemenkes Malang Jl. Besar Ijen No.77C Malang \\ dyah_widodo@poltekkes-malang.ac.id \\ (The Client's Experience Has A Family Structural Disorder In Caring For Clients At \\ Home)
}

\begin{abstract}
Abstrak: Keluarga merupakan lingkungan sosial yang terdekat yang sangat penting perannya dalam mewujudkan derajad kesehatan jiwa.. Tujuan penelitian menganalisis hubungan lamanya klien mengalami gangguan jiwa dengan stres keluarga dalam merawat klien gangguan jiwa di rumah. Jenis penelitian korelasional, dengan sampel sebagian keluarga yang tinggal serumah dengan klien gangguan jiwa di wilayah Jawa Timur Indonesia sesuai kriteria inklusi, besar sampel 200 orang diambil dengan teknik consecutive sampling. Pengumpulan data bulan Oktober-Nopember 2016 di Poli Kesehatan Jiwa Rumah Sakit Jiwa dr Radjiman Wediodiningrat Lawang. Instrumen penelitiannya kuesioner yang telah teruji validitas dan reliabilitasnya. Analisis data menggunakan uji statistik deskriptif dan Spearman Rho' dengan alpha 0,05. Hasil penelitian didapatkan bahwa ada hubungan lamanya klien mengalami gangguan jiwa dengan stres keluarga dalam merawat klien gangguan jiwa di rumah, dengan nilai p 0.026 dan nilai correlation coefficient -158 artinya kekuatan hubungan sangat lemah berlawanan arah, yaitu semakin lama klien mengalami gangguan jiwa maka semakin rendah tingkat stres yang dialami keluarga. Disarankan perlu diantisipasi munculnya stres pada keluarga gangguan jiwa dengan cara deteksi dini kesehatan anggota keluarga keluarga, pendampingan dan peningkatan pengetahuan dalam merawat gangguan jiwa untuk keluarga agar keluarga berkurang stresnya dan mampu merawat klien dengan lebih baik.
\end{abstract}

Kata kunci: lama gangguan jiwa, stres, keluarga

Abstract: The family is the closest social environment that is very important in its role in realizing the degree of mental health. The treatment of mental disorders that require a long time, various problems of client behavior and negative views of society about mental disorders is a high stressor for the family. The purpose of the study was to analyze the length of relationship between clients experiencing mental disorders and family stress in caring for clients with mental disorders at home. The type of correlational research, with a sample of some families living in a house with clients of mental disorders in the East Java region of Indonesia according to the inclusion criteria, the sample size of 200 people was taken by consecutive sampling technique. Data collection from October to November 2016 at the Psychiatric Mental Health Dr. Radjiman Wediodiningrat Lawang Mental Hospital. The research instrument was a questionnaire that had been tested for validity and reliability. Data analysis using descriptive statistical tests and Rho Spearman 'with alpha 0.05. The results showed that there was a long relationship between clients experiencing mental disorders and family stress in caring for clients with mental disorders at home, with a $\mathrm{p}$ value of 0.026 and correlation coefficient -158 means that the strength of the relationship is very weak in the opposite direction, ie the longer the client experiences mental disorders level of stress experienced by the family. It is recommended to anticipate the 
emergence of stress in the family of mental disorders by means of early detection of health of family members of the family, assistance and increased knowledge in treating mental disorders for the family so that the family is less stressed and able to treat clients better .

Key Word: old mental, stress, family disorders 


\section{PENDAHULUAN}

Gangguan jiwa perlu penanganan yang komprehensif. Besarnya angka gangguan jiwa di suatu wilayah memiliki pengaruh yang cukup besar dalam peningkatan angka morbiditas suatu bangsa, sekaligus penurunan terhadap angka produktivitas suatu negara untuk jangka panjang. Seseorang yang menderita gangguan jiwa kronis misalnya skizofrenia tidak akan bisa produktif dalam kehidupannya. Hal ini semakin diperjelas oleh WHO dalam merdeka.com (2013) tentang Global Burden Disease yang menjelaskan bahwa telah terjadi perubahan jenis penyakit yang menimbulkan beban bagi negara secara global ke arah penyakit kronis.

Jumlah klien gangguan jiwa dimungkinkan akan terus meningkat dari tahun ke tahun. IDI (Ikatan Dokter Indonesia) dalam IDIonline yang terbit 12 Oktober 2016 menyebutkan bahwa faktanya, satu dari empat orang dewasa akan mengalami masalah kesehatan jiwa pada satu waktu dalam hidupnya. Bahkan, setiap 40 detik di suatu tempat di dunia ada seseorang yang meninggal karena bunuh diri. Data WHO (2016) menunjukkan, terdapat sekitar 35 juta orang terkena depresi, 60 juta orang terkena bipolar, 21 juta terkena skizofrenia, serta 47,5 juta terkena demensia. Adapun hasil Riset Kesehatan Dasar tahun 2013 tentang prevalensi gangguan jiwa berat di Indonesia didapatkan prevalensi gangguan jiwa berat nasional sebesar 1,7 per 1.000 penduduk. Menyimak data tersebut, diketahui bahwa masalah gangguan jiwa khususnya di Indonesia bukan merupakan masalah yang sepele.

Gangguan jiwa adalah suatu sindrom atau pola psikologis secara klinis terjadi pada seorang dan dikaitkan dengan adanya distres, disability atau disertai peningkatan resiko kematian yang menyakitkan dan kehilangan kebebasan (Videbeck, 2008). Skizofrenia merupakan bentuk psikosis fungsional paling berat (Ingram, 1993). Seorang klien skizophrenia mengalami disorganisasi kepribadian yang cukup parah, distorsi realita dan ketidakmampuan berinteraksi dengan kehidupan sehari-hari (Ardani, 2008). Penyakit ini cenderung berlanjut atau kronis dan membutuhkan pengobatan dalam jangka waktu cukup lama.

Perawatan pada klien gangguan jiwa haruslah komprehensif dan holistik dari aspek biologis psikologis sosial dan spiritual. Rumah Sakit Jiwa bukanlah tempat perawatan seumur hidup bagi klien. Dalam kondisi yang telah membaik dan cukup stabil klien akan dipulangkan ke keluarganya.

Keluarga merupakan lingkungan sosial yang terdekat bagi seseorang. Sebagai unit terkecil di masyarakat keluarga memiliki peran yang sangat penting untuk mewujudkan derajad kesehatan. Dalam perawatan klien gangguan jiwa sangat butuh kesabaran. Peran keluarga merawat anggota keluarga saat selesai perawatan rumah sakit merupakan kunci utama untuk perkembangan dan kemajuan klien (Ratchaneekorn Kertchok, dkk. 2011). Friedman 2010 dalam Nuraenah (2012) menyatakan bahwa keluarga berkewajiban memberi pemenuhan kebutuhan dasar dan mengoptimalkan ketenangan jiwa bagi klien karena gangguan jiwa memerlukan terapi yang cukup lama, sehingga pengertian dan kerjasama keluarga sangat penting artinya dalam pengobatan.

Ketika klien telah berada di rumah maka tanggung jawab perawatan klien berada pada keluarga. Perilaku klien yang unik dan perawatan yang relatif lama, dapat memunculkan stres bagi anggota keluarga. Jika keluarga dipandang sebagai suatu sistem, maka masalah kesehatan yang 
dialami pada satu anggota keluarga akan mengganggu semua sistem atau keadaan keluarga tersebut (Nasir, A., 2011). Dampak yang dialami keluarga akibat adanya anggota keluarga yang gangguan jiwa antara lain keluarga mengalami rasa ketidaknyamanan, frustasi, cemas, putus asa, duka, kelelahan dan ketidakberdayaan karena telah hilangnya waktu rutinitas mereka selama perawatan dan pengobatan klien, akibatnya timbul penolakan keluarga terhadap klien yang cenderung menyalahkan klien gangguan jiwa sehingga kurang dukungan kepada klien (Nuraenah, 2012 dan Nasir, A., 2011).

Di sisi lain, beragam manifestasi klinis, gejala, maupun pengobatan yang terdapat pada klien gangguan jiwa dapat menimbulkan berbagai persepsi pada masyarakat. Persepsi negatif terkait klien gangguan jiwa yang sering dialami adalah labelling negatif bagi klien gangguan jiwa yang dapat berdampak terhadap timbulnya aib pada keluarga dan stigma negatif di masyarakat sekitarnya. Baron (2002) mendefinisikan stigma sebagai karakteristik seseorang yang dipersepsikan secara negatif oleh beberapa individu lain. Sikap negatif menciptakan praduga yang membentuk aksi negatif dan diskriminasi.

Fenomena yang terjadi saat ini adalah adanya penolakan keluarga terhadap klien skizofrenia. Salah satunya dibuktikan dengan upaya mereka menyembunyikan klien dari publik, termasuk dengan pasung. Memasung diartikan sebagai sebuah tindakan yang membelenggu seseorang ataupun memenjara dan seringkali dikucilkan oleh masyarakat. Tak jarang demi alasan keamanan banyak klien dipasung. Pemasungan klien gangguan jiwa pada umumnya terjadi karena ketidakmampuan keluarga dalam mengatasi kekambuhan gangguan jiwa, disamping itu keluarga juga malu dengan lingkungan atau masyarakat disekitarnya. Kondisi inilah yang justru akan menambah parahnya kondisi klien gangguan jiwa.

Kita menyadari bahwa masalah kesehatan yang dialami anggota keluarga pasti berdampak pada anggota keluarga lainnya, terlebih lagi untuk masalah gangguan jiwa. Tidak selalu semua anggota keluarga mampu menyesuaikan diri dengan baik terhadap setiap permasalahan yang terjadi dalam keluarganya. Akibatnya adalah terjadi masalah stres dalam keluarga tersebut. Perawatan yang membutuhkan waktu lama, perkembangan kondisi kesehatan klien juga lambat, serta berbagai permasalahan perilaku, dan stigma masyarakat yang dialami keluarga merupakan stresor tinggi bagi keluarga dengan anggota keluarga mengalami gangguan jiwa.

Stres pada keluarga gangguan jiwa dapat terjadi oleh karena stresor dari dalam keluarga yaitu kondisi kesehatan jiwa klien maupun dari lingkungannya berupa stigma negatif dari masyarakat. Hasil studi pendahuluan oleh peneliti dengan cara wawancara dengan keluarga didapatkan bahwa gangguan jiwa itu menakutkan, penampilannya menjijikkan, klien tidak paham bila diajak berbicara, susah disembuhkan dan diragukan kesembuhannya. Salah satu keluarga inti dari klien skizofrenia mengungkapkan bahwa keluarga terkadang merasa malu dan bingung dengan kondisi dan penampilan anaknya. Asumsi peneliti hal inilah yang dapat memicu munculnya stres pada keluarga yang memiliki anggota keluarga gangguan jiwa.

Berdasarkan uraian tersebut diatas maka perlu untuk dilakukan penelitian lebih mendalam tentang "Analisis faktor yang berhubungan dengan stres keluarga dalam merawat klien gangguan jiwa di rumah".

Tujuan penelitian ini adalah menganalisis hubungan lamanya klien mengalami gangguan jiwa dengan stres 
keluarga dalam merawat klien gangguan jiwa di rumah.

Manfaat penelitian adalah sebagai dasar untuk promosi kesehatan jiwa dan pencegahan masalah kesehatan jiwa pada keluarga selama merawat klien gangguan jiwa di rumah.

\section{METODE PENELITIAN}

Jenis penelitian ini adalah korelasional yaitu mencari keterkaitan antar variabel penelitian, dimana pengukuran variabel dilakukan satu kali tanpa intervensi penelitian.

Populasi dalam penelitian ini adalah keluarga yang tinggal serumah dengan klien gangguan jiwa di wilayah Jawa Timur Indonesia yang sedang mengantarkan klien periksa ulang kesehatan jiwanya di Poli Kesehatan Jiwa RSJ dr Radjiman Wediodiningrat Lawang.

Sampel dalam penelitian ini adalah sebagian dari populasi yang memenuhi ketentuan kriteria inklusi, yaitu

1) Salah satu anggota keluarga yang bertanggung jawab atas perawatan klien gangguan jiwa yang pernah mengalami rawat inap di Rumah Sakit Jiwa atau Ruang Rawat Jiwa di Rumah Sakit Umum.

2) Tinggal serumah dengan klien gangguan jiwa di wilayah Jawa Timur Indonesia

3) Sedang mengantarkan klien periksa ulang kesehatan jiwanya di Poli Kesehatan Jiwa Rumah Sakit Jiwa dr. Radjiman Wediodiningrat Lawang.

4) Usia > 17 tahun

5) Bersedia menjadi responden.

Penentuan besar sampel pada penelitian ini menggunakan tabel dari Sugiono (2010), dimana untuk estimasi populasi yang sesuai kriteria inklusi lebih kurang 500 orang dan taraf signifikansi 5\% maka besar sampelnya adalah 200 orang.
Teknik pengambilan sampelnya adalah consecutive sampling yaitu metode sampling yang memberi kemungkinan yang sama bagi setiap unsur dalam populasi untuk dipilih namun disesuaikan dengan tujuan penelitian.

Variabel penelitian terdiri dari variabel bebas dan variabel terikat. Variabel bebasnya adalah lamanya klien mengalami gangguan jiwa dan variabel terikatnya adalah stres dalam merawat klien gangguan jiwa di rumah.

Instrumen pengumpulan datanya adalah kuesioner yang telah teruji validitas dan reliabilitasnya. Pengumpulan data dilaksanakan di Poli Kesehatan Jiwa Rumah Sakit Jiwa dr. Radjiman Wediodiningrat Lawang pada bulan Oktober sampai dengan Nopember 2016. Peneliti memperhatikan kaidah etik penelitian saat pengumpulan data tersebut.

Adapun hipotesis penelitian ini yaitu: Ada hubungan lamanya klien mengalami gangguan jiwa dengan stres keluarga dalam merawat klien gangguan jiwa di rumah.

Data dianalisis secara statistik dengan menggunakan uji statistik deskriptif frekuensi dan crosstabulasi, serta uji korelasi non parametrik (Spearman Rho') dengan alpha 0,05 .

\section{HASIL PENELITIAN}

Pada bagian ini disajikan data umum tentang identitas responden dan identitas klien gangguan jiwa, dan data khusus tentang lamanya klien mengalami gangguan jiwa yang berhubungan dengan stres keluarga dalam merawat klien gangguan jiwa di rumah sesuai tujuan penelitian.

\section{Data Umum}

Data keluarga responden penelitian sebagai berikut: 
Tabel 1. Karakteristik Responden

\begin{tabular}{|l|l|l|}
\hline No & \multicolumn{1}{|c|}{$\begin{array}{c}\text { Identitas } \\
\text { Responden }\end{array}$} & \multicolumn{1}{|c|}{ Hasil Penelitian } \\
\hline 1 & Jenis kelamin & $\begin{array}{l}\text { Perempuan 52\%; Laki-laki } \\
48 \%\end{array}$ \\
\hline 2 & Umur & Rata-rata 48,6 tahun \\
\hline 3 & Pendidikan & Sekolah Dasar 41,5\% \\
\hline 4 & Pekerjaan & Karyawan swasta 59\% \\
\hline 5 & $\begin{array}{l}\text { Hubungan } \\
\text { kekerabatan/ } \\
\text { saudara }\end{array}$ & Orangtua 54, 5\% \\
\hline
\end{tabular}

Berdasarkan tabel no 1 tersebut dapat diketahui bahwa responden mayoritas adalah perempuan dengan usia rata-rata 48,6 tahun yang tergolong dalam usia dewasa menengah, mayoritas berpendidikan Sekolah Dasar (6 tahun) dan merupakan orang tua dari klien gangguan jiwa.

Adapun karakteristik klien gangguan jiwa yang dirawat oleh responden sebagai berikut:

Tabel 2. Karakteristik klien Gangguan Jiwa

\begin{tabular}{|c|l|l|}
\hline No & \multicolumn{1}{|c|}{ Identitas Klien } & \multicolumn{1}{c|}{ Hasil Penelitian } \\
\hline 1 & Jenis kelamin & $\begin{array}{l}\text { Laki-laki 68\%; } \\
\text { Perempuan 32\% }\end{array}$ \\
\hline 2 & Umur & Rata-rata 34,2 tahun \\
\hline 3 & Pendidikan & Rata- rata 9,2 tahun \\
\hline
\end{tabular}

Berdasarkan tabel no 2 diketahui bahwa klien mayoritas adalah laki-laki berusia 24,8 tahun yang tergolong dalam usia dewasa menengah dan rata-rata pendidikan adalah tamatan Sekolah Menengah Pertama (9 tahun).

\section{Data Khusus}

Tingkat stres yang dialami responden selama merawat keluarganya yang menderita gangguan jiwa dapat dilihat pada tabel no 3 berikut:

Tabel 3. Tingkat stres responden

\begin{tabular}{llll}
\hline No & Tingkat stres & Frekuensi & Persentase \\
\hline
\end{tabular}

\begin{tabular}{llrr}
\hline 1 & Stres berat & 22 & 11,0 \\
2 & Stres sedang & 35 & 17,5 \\
3 & Stres ringan & 143 & 71,5 \\
\hline & Total & 200 & 100,0 \\
\hline
\end{tabular}

Tabel no 3 menunjukkan bahwa mayoritas keluarga $(71,5 \%)$ mengalami stres ringan selama merawat keluarga yang mengalami gangguan jiwa di rumah.

Hasil uji korelasi Spearman Rho' antara lamanya klien mengalami gangguan jiwa dengan tingkat stres didapatkan nilai $\mathrm{p}$ atau sig-2 tailed adalah 0.026 lebih kecil dari alpha 0.05, sehingga disimpulkan bahwa ada hubungan lamanya klien mengalami gangguan jiwa dengan tingkat stres keluarga dalam merawat klien gangguan jiwa di rumah. Adapun nilai correlation coefficient adalah -158 artinya kekuatan hubungan sangat lemah dengan berlawanan arah, yaitu semakin lama klien mengalami gangguan jiwa maka semakin rendah tingkat stres yang dialami keluarga.

\section{PEMBAHASAN}

Stres merupakan mekanisme yang kompleks dan menghasilkan respons yang saling terkait, baik fisiologis, psikologis maupun perilaku pada individu yang mengalaminya. Stres merupakan reaksi fisiologis dan psikologis yang terjadi ketika seseorang merasakan ketidakseimbangan antara tuntutan yang dihadapi dengan kemampuannya untuk mengatasi tuntutan tersebut (Nasir, 2011).

Hasil penelitian menunjukkan bahwa meskipun mayoritas responden mengalami stres ringan. Pada dasarnya stres ringan ini dapat bermanfaat bagi keluarga untuk selalu waspada terhadap kemungkinan terjadinya kekambuhan pada klien gangguan jiwa.

Aspek menarik dari hasil penelitian ini adalah stres berat lebih banyak dialami responden laki-laki dengan prosentase $54.5 \%$, sedangkan kondisi stres sedang pada 
responden perempuan lebih tinggi hampir dua kali lipat dengan prosentase $62.9 \%$. Stres menurut Hans Selye (1976, dalam Maramis 2009) merupakan respon tubuh yang bersifat tidak spesifik terhadap setiap tuntutan atau beban atasnya dan Maramis (1999) menyatakan bahwa stres adalah sesuatu yang mengganggu keseimbangan kita, segala masalah atau tuntutan penyesuaian diri.

Hasil uji korelasi Spearman Rho' disimpulkan bahwa ada hubungan lamanya klien mengalami gangguan jiwa dengan tingkat stres keluarga dalam merawat klien gangguan jiwa di rumah. Kekuatan hubungannya sangat lemah berlawanan arah, artinya semakin lama klien mengalami gangguan jiwa maka semakin rendah tingkat stres yang dialami keluarga.

$$
\text { Keluarga merupakan sistem }
$$
pendukung utama yang memberi perawatan langsung pada setiap keadaan (sehat-sakit) klien. Umumnya, keluarga meminta bantuan tenaga kesehatan jika mereka tidak sanggup merawatnya. Oleh karena itu asuhan keperawatan yang berfokus pada keluarga bukan hanya untuk memulihkan keadaan klien tetapi bertujuan untuk mengembangkan dan meningkatkan kemampuan keluarga dalam mengatasi masalah kesehatan dalam keluarga tersebut (Yosep, 2007). Dengan kurun waktu yang relatif lama maka kemampuan keluarga mengatasi masalah akan semakin baik, kemampuan adaptasi terhadap permasalahan juga semakin baik sehingga stres yang dialami keluarga semakin rendah.

Dalam kehidupan keluarga pasti terjadi interaksi didalamnya. King (Christensen \& Kenney, 1995) mendefenisikan interaksi sebagai suatu proses dari persepsi dan komunikasi antara individu dengan individu, individu dengan kelompok, individu dengan lingkungan yang dimanifestasikan sebagai perilaku verbal dan non verbal dalam mencapai tujuan (Christensen J.P, 2009).

Keluarga yang mempunyai kemampuan mengatasi masalah akan dapat mencegah perilaku maladaptif (pencegahan primer), menanggulangi perilaku maladaptif (pencegahan sekunder) dan memulihkan perilaku adaptif (pencegahan tersier), maka derajat kesehatan klien dan keluarga dapat ditingkatkan secara optimal (Keliat, 2005). Jika keluarga dalam kondisi stres karena merawat klien gangguan jiwa di rumah maka kemampuan mengatasi masalah akan berkurang. Kondisi stres yang dialami keluarga ini dapat berdampak pada kurang optimalnya dalam merawat klien, mencegah perilaku maladaptif yang terjadi pada klien.

\section{KESIMPULAN DAN SARAN}

\section{Kesimpulan}

Ada hubungan lamanya klien mengalami gangguan jiwa dengan stres keluarga dalam merawat klien gangguan jiwa di rumah, dengan nilai $\mathrm{p}$ 0.026. dan nilai correlation coefficient -158 artinya kekuatan hubungan sangat lemah berlawanan arah, dimana semakin lama klien mengalami gangguan jiwa maka semakin rendah tingkat stres yang dialami keluarga.

\section{Saran}

1. Perlu diantisipasi munculnya stres pada keluarga gangguan jiwa dengan cara deteksi dini kesehatan anggota keluarga keluarga melalui kunjungan rumah oleh petugas kesehatan

3. Perlu adanya pendampingan dan peningkatan pengetahuan dalam merawat gangguan jiwa untuk keluarga yang memiliki anggota keluarga gangguan jiwa oleh petugas kesehatan agar keluarga berkurang 
stresnya dan mampu merawat klien dengan lebih baik.

\section{DAFTAR PUSTAKA}

Ardani, T. A. 2008. Psikiatri Islam. Malang: Malang press.

Baron, R. A, \& Byrne, D. E. 2002. Social Psychology. USA : Pearson

Christensen, Paula J. 2009. Nursing Process: Aplication of Conceptual Models, 4th ed. St.Louis: Mosby-Year Book, Inc.

Christensen, Paula J.\& Kenney, Janet W. 1996. Proses Keperawatan: Aplikasi model konseptual, ed 4 terjemahan. Jakarta: Penerbit Buku Kedokteran EGC.

Ingram, I. M., Timbury, G.C., dan Mowbray, R.M. 1993. Psikiatri: Catatan Kuliah. Jakarta: EGC.

Keliat, B.A. 2005. Proses Keperawatan Jiwa. Edisi 1, . Jakarta : EGC

Maramis W.F \& Maramis A.A. 2009. Catatan Ilmu Kedokteran Jiwa, Surabaya: Airlangga University Press

Nasir, A. et al. 2011. Dasar-Dasar Keperawatan Jiwa. Jakarta: Salemba Medika

Notoatmodjo, s, 2005, Promosi kesehatan teori dan Aplikasi, Jakarta : PT Rineka Cipta

Nuraenah, 2012. Hubungan antara dukungan keluarga dan beban keluarga dalam merawat anggota dengan riwayat perilaku kekerasan di Rumah sakit Jiwa Islam Klender Jakarta Timur 2012. Program Magister Ilmu Keperawatan Universitas Indonesia, Depok. Diakses pada tanggal 1 agustus 2017.

Peraturan Pemerintah Nomor 21 Tahun 1994 tentang Penyelenggaraan Pembangunan Keluarga Sejahtera

Santrock, John. W. 2012. Life-Span Development Thirteen Edition Jilid 2. Surabaya: Penerbit Erlangga

Suprajitno, 2004. Asuhan Keperawatan Keluarga: Aplikasi dalam praktik, Jakarta : EGC

Videbeck, S. L. 2008. Buku Ajar Keperawatan Jiwa. Jakarta: EGC

Yosep, Iyus. 2007. Keperawatan Jiwa. Bandung : Refika Aditama

.http://www.idionline.org/berita/ha ri-kesehatan-jiwa-sedunia-penyebabmunculnya-gangguan-kesehatan-jiwa/ Hari Kesehatan Jiwa Sedunia : Penyebab Munculnya Gangguan Kesehatan Jiwa, 12 October 2016 | Posted in Berita, berita-lengkap, newsnasional, diakses 25 September 2017, pukul 19.30 WIB 